\title{
Proposal of stiffness of triple spring of a passenger railway vehicle
}

\author{
Andrej Suchánek ${ }^{1, *}$, Jozef Harušinec $^{1}$, Mária Loulová ${ }^{1}$ and Pavol Kurčík ${ }^{1}$ \\ ${ }^{1}$ University of Žilina, Faculty of Mechanical Engineering, Department of Transport and Handling Machines, Univerzitná 8215/1, 010 26 \\ Žilina, Slovak Republic
}

\begin{abstract}
The article deals with the calculation of stiffness of a secondary suspension spring built in a bogie of a rail vehicle with a tilting car body. The vertical stiffness of the springs was calculated using the ANSYS program. The results were compared with calculated values afterwards. The lateral stiffness was evaluated in a similar manner. Analyt-ical method by Gross, Wahl, Budrick, Timoshenko and Ponomarieva was used for comparison with numerical values. The ANSYS simulation was performed for calculating the vertical stiffness of the triple springs. The most suitable analytical method is a method by Timoshenko and Ponomarieva, where the percentage difference was the smallest. The obtained data will be used as an input for the design of coil springs which will be implemented in a model of a vehicle with a tilting car body, for which the comfort values during transition in curve will eventually be determined.
\end{abstract}

\section{Introduction}

Spring makes an important part of complex mechanical systems $[1,2,5,9,10,13]$. By choosing a proper shape and material it is able to accumulate deformation energy. In mechanical engineering, they serve mostly to cushion a part of a tool or to produce pressure $[6,12]$. Because of these properties, coil springs are used in construction of rail vehicle bogies as well. In case of using the coil springs in rail vehicle with tilting car body, the main function is to increase the tilt during transition in curve and therefore to decrease the impact of unbalanced lateral acceleration on passengers $[3,4,8,11,14]$.

When modeling the bogie in CAD software CATIA it was necessary to determine its parameters needed for its later analysis in SIMPACK 9.8 program. In the article we will therefore deal with coil springs of the secondary suspension. We will set the force element in SIMPACK program, used for modeling springs and focus on determination of the spring stiffness. Spring valuse have been defined using analytical methods and compared with numerical results taken from the simulation program ANSYS R15.0 afterwards. The bogie model, imported to SIMPACK, is displayed in the Fig. 1.

\section{Spring parameters necessary for the calculation}

SIMPACK allows generation of a spring along the positive direction of the $\mathrm{x}$-axis of a reference marker, which is located in the centre of the ground end of the spring. Stiffness of the coil springs is given by wire diameter $d$, number of active coils $n$, number of end coils $n_{0}$, free spring length $h_{0}$, pitch $s$. The free spring length is to be chosen in such manner, that even by its maximal compression $z_{\max }$ (restricted by bump stop) the single coils would not touch each other, but a clearance of cca 10 to $15 \%$ of a wire diameter is to be held $[11,12]$.

The basic input parameters in SIMPACK program for the Spring-Damper Parallel Cmp Force element are [15]:

- nominal forces $F_{n o m_{-} x}, F_{n o m_{-} y}, F_{n o m_{-} z}$ (Nominal force f_nom_x/y/z),

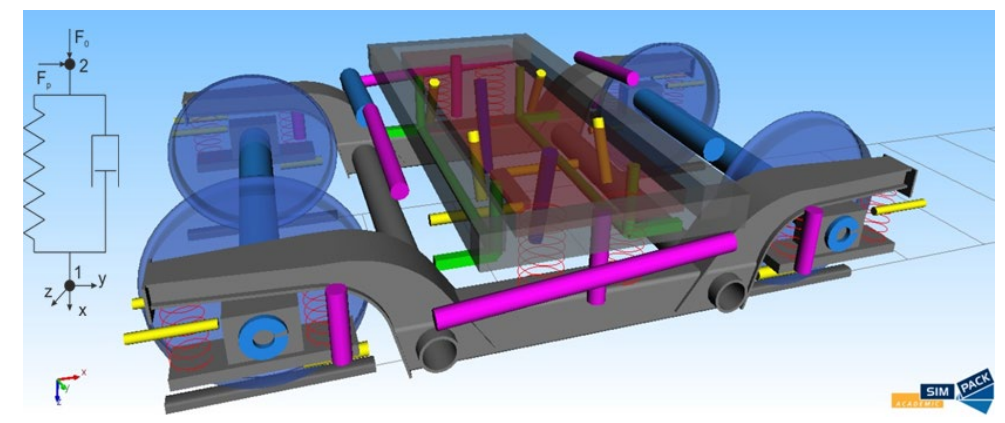

Fig. 1 Location of the suspension in a bogie.

\footnotetext{
* Corresponding author: andrej.suchanek@,fstroj.uniza.sk
} 
- $\quad$ stiffness $k_{x}, k_{y}, k_{z}($ Stiffness k_x/y/z),

- damping $d_{x}, d_{y}, d_{z}$ (Damping d_x/y/z),

- imput function $F_{k x}, F_{k y}, F_{k z}, F_{d x}, F_{d y}, F_{d z}$ (Input

Function $\mathrm{F}_{-} \mathrm{k}(\mathrm{x} / \mathrm{y} / \mathrm{z})$, Input Function $\mathrm{F}_{-} \mathrm{d}(\mathrm{xd} / \mathrm{yd} / \mathrm{zd})$,

- $\quad$ clearance in direction $x, y, z, s_{x}, s_{y}, s_{z}$,

- root function - used for detection of the clearance constraints,

- reference marker for measurements and calculation all the measurements of distance and speed between markers as well as all calculated forces use directions defined by the axis of the reference marker instead of From Marker,

- forces $F_{x}, F_{y}, F_{z}$ which describe the forces in three directions.

\section{Determination of vertical stiffness of the springs}

Coil springs represent the most proper steel suspension element in the suspension system of rail vehicles. They are favourable in the means of dimensions and mass. They are used in systems along with dampers, because they do not have the ability to absorb the energy of oscillating motion of parts.

For the coil spring stiffness calculation, the formula (1) applies, which was used for analytical determination of individual vertical stiffness values. These were compared with values taken from ANSYS afterwards (Tab. 2):

$$
k_{z}=\frac{G \cdot d^{4}}{64 \cdot D^{3} \cdot n}\left[N \cdot m m^{-1}\right]
$$

Where:

G...Shear modulus [Pa],

d...Wire diameter [mm],

D...Diameter of spring [mm],

n...number of active coils [-].

In the following Tab. 1, basic parameters of coil springs used in the bogie model are displayed.

Table 1 Parameters of the coil springs. boundary condition, a vertical displacement (along $\mathrm{z}$ axis) value of $50 \mathrm{~mm}$ was set. The manner of end coils placing is displayed in Fig. 2. After carrying out simulations and displaying results for individual springs A (outer), B (middle) and C (inner), we found the value of vertical force acting on the spring. From the rate of acting force and spring compression we determined the result value of vertical spring stiffness.

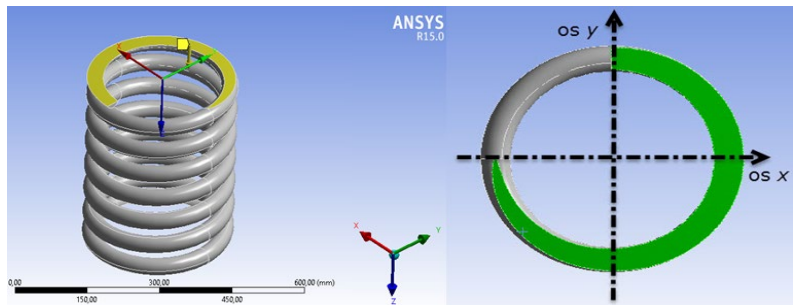

Fig. 2 Model of loaded coilspring A in ANSYS.

\section{Determination of lateral spring stiffness}

For the analytical calculation of lateral stiffness, many formulas from various authors were derived, but they are only approximate and do not apply in general, because they do not regard all the affecting factors [11]. For the analytical determination of the spring stiffness, formulas by Gross, by Wahl, by Budrick and by Tymoshenko and Ponomariov have been used.

- Calculation by Gross:

Stiffness of a spring under load in lateral direction:

$$
\begin{aligned}
k_{y} & =\frac{1}{\frac{1}{F_{0}} \cdot\left[\frac{2}{\alpha} \cdot \operatorname{tg}\left(\alpha \cdot \frac{h}{2}\right)-h\right]+\frac{h}{k_{s}}}\left[N \cdot \mathrm{mm}^{-1}\right], \text { where: } \\
\alpha & =\sqrt{\frac{F_{0}}{k_{0}\left(1-\frac{F_{0}}{k_{s}}\right)}[-] \text { is a constant. }}
\end{aligned}
$$

Where:

$\mathrm{k}_{0} \ldots$ Bending stiffness $\left[\mathrm{N} . \mathrm{mm}^{-1}\right]$,

$\mathrm{k}_{\mathrm{s}}$... Shear stiffness [N.mm ${ }^{-1}$.

\begin{tabular}{|c|r|r|r|r|r|r|r|r|r|}
\hline Spring & \multicolumn{1}{c|}{$\begin{array}{c}\mathbf{d} \\
{[\mathbf{m m}]}\end{array}$} & $\begin{array}{c}\text { D } \\
{[\mathbf{m m}]}\end{array}$ & \multicolumn{1}{c|}{$\begin{array}{c}\mathbf{n} \\
{[-]}\end{array}$} & $\begin{array}{c}\mathbf{s} \\
{[\mathbf{m m}]}\end{array}$ & \multicolumn{1}{c|}{$\begin{array}{c}\mathbf{n}_{\mathbf{0}} \\
{[-]}\end{array}$} & $\begin{array}{c}\mathbf{h} \\
{[\mathbf{m m}]}\end{array}$ & \multicolumn{1}{c|}{$\begin{array}{c}\mathbf{F}_{\mathbf{0}} \\
{[\mathbf{N}]}\end{array}$} & $\begin{array}{c}\mathbf{E} \\
{[\mathbf{M P a}]}\end{array}$ & $\begin{array}{c}\mathbf{G} \\
{[\mathbf{M P a}]}\end{array}$ \\
\hline $\mathrm{A}$ & 35 & 280 & 6 & 56.67 & 0.75 & 375 & 5707.10 & $2.06 .10^{5}$ & $8.15 .10^{4}$ \\
\hline $\mathrm{B}$ & 25 & 210 & 7 & 50.00 & 0.75 & 375 & 3021.10 & $2.06 .10^{5}$ & $8.15 .10^{4}$ \\
\hline C & 20 & 150 & 8 & 44.38 & 0.75 & 375 & 2983.70 & $2.06 .10^{5}$ & $8.15 .10^{4}$ \\
\hline
\end{tabular}

Table 2 Coil springs vertical stiffness comparison.

\begin{tabular}{|c|r|r|r|r|}
\hline Spring & $\begin{array}{c}\text { Analytically determined stiffness }-\mathbf{k}_{\mathbf{z}} \\
{\left[\mathbf{N} . \mathbf{m m}^{-1} \text { ] }\right.}\end{array}$ & $\begin{array}{c}\text { Stiffness determined in ANSYS - } \mathbf{k}_{\mathbf{z}} \\
{\left[\mathbf{N} . \mathbf{m m}^{-1}\right]}\end{array}$ & $\begin{array}{c}\text { Difference } \\
{[\%]}\end{array}$ \\
\hline $\mathrm{A}$ & 103.17 & 114.50 & 9.90 \\
\hline $\mathrm{B}$ & 55.45 & 59.74 & 7.19 \\
\hline $\mathrm{C}$ & 54.57 & 60.89 & 10.37 \\
\hline
\end{tabular}

Geometrical model of individual springs was created in

CATIA and imported to ANSYS afterwards. As a 
Bending stiffness:

$$
k_{0}=\frac{h}{\pi \cdot n \cdot \frac{D}{2} \cdot\left(\frac{1}{E \cdot I_{1}}+\frac{1}{G \cdot I_{p}}\right)}\left[N \cdot \mathrm{mm}^{-1}\right]
$$

Where:

E...spring length $[\mathrm{mm}]$,

D...Wire diameter [mm],

$\pi$...mathematical constant [-],

$\mathrm{I}_{1} \ldots$ Moment of inertia $\left[\mathrm{kg} \cdot \mathrm{m}^{2}\right]$,

$\mathrm{I}_{\mathrm{p}}$...Polar moment of area $\left[\mathrm{kg} \cdot \mathrm{m}^{2}\right]$.

Shear stiffness:

$$
k_{s}=\frac{E \cdot h \cdot I_{1}}{\pi \cdot n \cdot\left(\frac{D}{2}\right)^{3}}\left[N \cdot m^{-1}\right] .
$$

Moment of inertia:

$$
I_{1}=\frac{\pi \cdot d^{4}}{64}\left[\mathrm{~kg} \cdot \mathrm{mm}^{2}\right]
$$

Polar moment of area:

$$
I_{p}=\frac{\pi \cdot d^{4}}{32}\left[\mathrm{~kg} \cdot \mathrm{mm}^{2}\right]
$$

- Calculation by Wahl:

Stiffness of a spring under load in lateral direction:

$k_{y}=\frac{2.6 \cdot k_{z}}{1+0.77 \cdot \beta^{2}} \cdot\left(1-\frac{F_{0}}{U \cdot h_{0} \cdot k_{z}}\right)\left[N . m m^{-1}\right]$,

where: $\beta=\frac{h}{D}$ is a constant.

Table 3 Dependency of the $U$ coefficient from $\beta$.

\begin{tabular}{|l|l|l|l|l|l|l|l|l|}
\hline$\beta$ & 1.5 & 2 & 2.5 & 3 & 3.5 & 4 & 4.5 & 5 \\
\hline $\mathrm{U}$ & 0.69 & 0.63 & 0.53 & 0.39 & 0.27 & 0.2 & 0.14 & 0.11 \\
\hline
\end{tabular}

- Calculation by Budrick:

Stiffness of a spring under load in lateral direction:

$$
k_{y}=k_{z} \cdot \frac{G}{E} \cdot\left(1+\frac{2+\mu}{3} \cdot \beta^{2}\right)\left[N \cdot m m^{-1}\right] \text {. }
$$

Where:

$$
\begin{aligned}
& k_{z}=\frac{2}{\pi \cdot D \cdot n \cdot\left(\frac{h^{2}}{12} \cdot\left(\frac{1}{G \cdot I_{p}}+\frac{1}{E \cdot I_{l}}\right)+\frac{D^{2}}{4 \cdot E \cdot I_{l}}\right)} \\
& {\left[N \cdot \mathrm{mm}^{-1}\right]}
\end{aligned}
$$

- Calculation by Tymoshenko and Ponomariov:

Stiffness of a spring under load in lateral direction:

$$
k_{y}=k_{z} \cdot \frac{D^{2} \cdot(1-\gamma)}{\frac{0.2936 \cdot(h-\chi \cdot d)^{3}}{(h-1.5 \cdot h \cdot d)}+0.381 \cdot D^{2}}\left[N \cdot \mathrm{mm}^{-1}\right],
$$

Where:

$\gamma \ldots$ variable quantity $[-]$,

$\chi$...Constant [-],

$$
\begin{aligned}
& \text { for } \beta_{0}<2,62: \gamma=0.375 \cdot \frac{F_{0}}{k_{z} \cdot h} \cdot \beta \cdot\left(\beta-1.5 \cdot \frac{d}{D}\right), \\
& \text { for } \beta_{0}>2,62: \gamma=\frac{\frac{F_{0}}{k_{z} \cdot h} \cdot \beta}{0.813 \cdot\left(\beta_{0}-\sqrt{\beta_{0}^{2}-6.87}\right)}
\end{aligned}
$$

In formula (10) there is non-dimensional variable quantity $\gamma$, which is dependant on slenderness ratio of a loaded spring. Its value can be calculated from formulas (11) and (12). The constant $\chi$ is an auxiliary

\begin{tabular}{|c|c|c|c|}
\hline Method & $\mathbf{A}$ & $\mathbf{B}$ & $\mathrm{C}$ \\
\hline ANSYS ky $\left[\mathrm{Nmm}^{-1}\right]$ & 172.12 & 38.28 & 35.47 \\
\hline ANSYS $\mathrm{k}_{\mathrm{x}}\left[\mathrm{Nmm}^{-1}\right]$ & 142.99 & 50.36 & 25.60 \\
\hline Grossa $\left[\mathrm{Nmm}^{-1}\right]$ & 100.36 & 34.18 & 15.90 \\
\hline Wahla $\left[\mathrm{Nmm}^{-1}\right]$ & 88.57 & 32.10 & 17.70 \\
\hline Budricka $\left[\mathrm{Nmm}^{-1}\right]$ & 179.49 & 78,99 & 66.85 \\
\hline $\begin{array}{l}\text { Timošenka and } \\
\text { Ponomarieva }\left[\mathrm{Nmm}^{-1}\right]\end{array}$ & 109.40 & 37.13 & 17.60 \\
\hline \multicolumn{4}{|c|}{$\begin{array}{c}\text { Percentage of difference between results from } \\
\text { individual methods and ANSYS }\end{array}$} \\
\hline G-A-ky [\%] & 41.69 & 10.70 & 55.18 \\
\hline G-A-kx [\%] & 29.81 & 32.13 & 37.89 \\
\hline W-A-ky $[\%]$ & 48.54 & 16.14 & 50.11 \\
\hline W-A-kx $[\%]$ & 38.06 & 36.26 & 30.88 \\
\hline $\mathrm{B}-\mathrm{A}-\mathrm{k}_{\mathrm{y}}[\%]$ & 4.28 & 106.37 & 88.46 \\
\hline $\mathrm{B}-\mathrm{A}-\mathrm{k}_{\mathrm{x}}[\%]$ & 25.53 & 56.85 & 161.13 \\
\hline TaP-A-ky $[\%]$ & 36.44 & 2.99 & 50.37 \\
\hline TaP-A-kx $[\%]$ & 23.49 & 26.26 & 31.23 \\
\hline
\end{tabular}
quantity, which regards the manner of mounting the end coils of the springs (joint or rigid mounting). For the analysed springs, the constant is equal $0.5[5,8]$. We defined the values of lateral stiffness analytically, based on formulas according to individual methods (2-12). These values were afterwards compared with the values obtained from ANSYS. Input parameters of the individual springs are given in Tab.4.

Table 4 Calculated values and values obtained from ANSYS.

In ANSYS, we determined the lateral stiffness values similarly to vertical stiffness, but besides the $50 \mathrm{~mm}$ vertical displacement (compression) in z-axis direction, a lateral displacement of $1-5 \mathrm{~mm}$ in the $\mathrm{x}$ - and y-axis direction was set for the individual springs. The calculation was performed separately for the displacement in $\mathrm{x}$-axis and in $\mathrm{y}$-axis direction. The result values of the vertical force $F_{0}$ were used in analytical determination of stiffness. The lateral stiffness obtained from ANSYS was defined as proportion of the obtained lateral force to the lateral displacement. The calculated values and values obtained from ANSYS are in Tab. 4.

\section{Determination of the triple spring stiffness}

The secondary suspension of the analysed bogie is consists of three coil springs (Fig. 5). Lateral forces in springs $F_{p}$ have been calculated using the ANSYS program for 8 different mounting positions of the end 
coil (Fig. 4). The maximal vertical displacement was set to the value of $50 \mathrm{~mm}$ and the lateral displacement was in the range of $0-4 \mathrm{~mm}$. In Fig. 3 we can see the characteristic of the triple spring lateral forces in dependency on lateral displacement. If we turn the spring system around the vertical axis (45 degrees) the characteristic is shifting. As can be seen in Fig. 3, the mounting positions of the end coil P0 and P180 appear to be most suitable (Fig. 4). The resulting vertical stiffness of the triple spring is constant with a value of $221.88 \mathrm{Nmm}^{-1}$ with an applied vertical force of $11091.22 \mathrm{~N}$. The calculated values of lateral forces $F_{p}$ are in the following Tab. 5. We determined the lateral stiffness for the position of the end coils P180 (Tab. 6), its value is linear and rises with increasing lateral displacement.

Table 5 Calculated values of the lateral forces.

\begin{tabular}{|c|c|c|c|}
\hline $\begin{array}{c}\text { Lateral } \\
\text { dispacement }[\mathrm{mm}]\end{array}$ & $\begin{array}{l}\text { FP0 } \\
{[\mathbf{N}]}\end{array}$ & $\begin{array}{l}\mathbf{F}_{\mathbf{P} 45} \\
{[\mathbf{N}]}\end{array}$ & $\begin{array}{l}\text { FP90 } \\
{[\mathbf{N}]}\end{array}$ \\
\hline 4 & 809.21 & 1066.50 & 1165.30 \\
\hline 3 & 636.54 & 862.84 & 975.62 \\
\hline 2 & 434.30 & 659.07 & 753.84 \\
\hline 1 & 232.00 & 454.90 & 547.72 \\
\hline 0 & 2.99 & 251.72 & 342.89 \\
\hline \multicolumn{4}{|c|}{$\begin{array}{l}\text { Table } 6 \text { Calculated values of secondary suspension lateral } \\
\text { stiffness for the spring mounting position P180. }\end{array}$} \\
\hline $\begin{array}{l}\text { Lateral dispacement } \\
{[\mathrm{mm}]}\end{array}$ & $\begin{array}{l}\text { FP180 } \\
{[\mathbf{N}]}\end{array}$ & \multicolumn{2}{|c|}{$\begin{array}{l}\text { Lateral stiffness } \mathrm{k}_{\mathrm{y}} \\
\quad\left[\mathrm{Nmm}^{-1}\right]\end{array}$} \\
\hline 4 & 780.43 & & 195.11 \\
\hline 3 & 578.80 & & 192.93 \\
\hline 2 & 374.85 & & 187.43 \\
\hline 1 & 174.96 & & 174.96 \\
\hline
\end{tabular}

\begin{tabular}{|c|c|c|c|c|c|c|c|c|}
\hline $\begin{array}{c}\text { Lateral } \\
\text { dispacement }[\mathrm{mm}]\end{array}$ & $\begin{array}{l}F_{P 0} \\
{[N]}\end{array}$ & $\begin{array}{l}\text { F P45 }_{\text {P }} \\
{[\mathbf{N}]}\end{array}$ & $\begin{array}{l}\text { FP90 }_{\mathbf{P}} \\
{[\mathbf{N}]}\end{array}$ & $\begin{array}{c}\mathbf{F}_{\mathbf{P} 135} \\
{[\mathbf{N}]}\end{array}$ & $\begin{array}{c}\text { FP180 }_{10} \\
{[\mathbf{N}]}\end{array}$ & $\begin{array}{c}\text { FP225 }_{2} \\
{[\mathbf{N}]}\end{array}$ & $\begin{array}{c}\text { FP270 } \\
{[\mathbf{N}]}\end{array}$ & $\begin{array}{c}\mathbf{F}_{\mathbf{P} 315} \\
{[\mathbf{N}]}\end{array}$ \\
\hline 4 & 809.21 & 1066.50 & 1165.30 & 1071.80 & 780.43 & 569.23 & 481,09 & 559.77 \\
\hline 3 & 636.54 & 862.84 & 975.62 & 866.24 & 578.80 & 359.50 & 274.78 & 355.94 \\
\hline 2 & 434.30 & 659.07 & 753.84 & 661.52 & 374.85 & 155.58 & 69.04 & 155.44 \\
\hline 1 & 232.00 & 454.90 & 547.72 & 457.33 & 174.96 & -47.52 & -136.86 & -48.64 \\
\hline 0 & 2.99 & 251.72 & 342.89 & 253.00 & 2.99 & -251.72 & -342.89 & -253.00 \\
\hline
\end{tabular}

Table 6 Calculated values of secondary suspension lateral

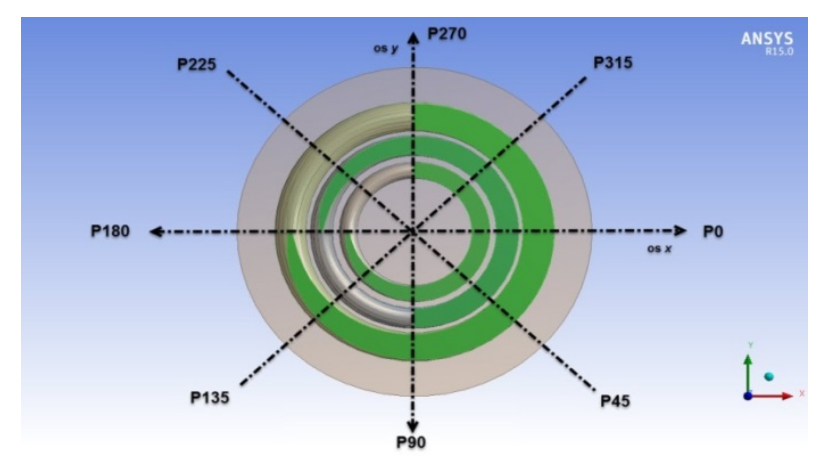

Fig. 4 Spring end coil mounting positions.

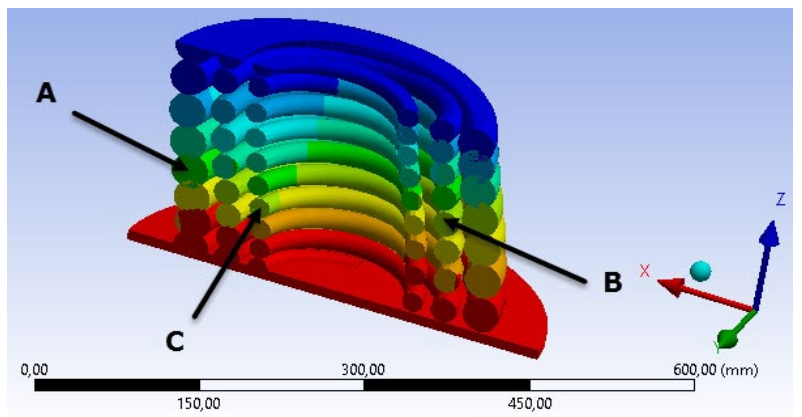

Fig. 5 Model of a loaded coil spring in program ANSYS.

\section{Conclusion}

Suspension is one of the most important parts of a bogie. In this article we focused on the secondary suspension, consisting of three coil springs. Stiffness of the individual springs was examined separately using analytical methods and numerical calculation.

When determing the vertical stiffness, the difference 
between calculated values and values obtained from ANSYS was about $10 \%$ in average, which is sufficient for use in SIMPACK program. After determination of lateral stiffness using individual analytical methods and consequential comparison with values obtained using numerical method we discovered that the method by Tymoshenko and Ponomariev, where the percentage difference was the smallest, is the most suitable. From the above can be concluded, that not every analytical method is suitable for determination of lateral stiffness of coil springs.

The advantage of using numerical method for spring stiffness determination and using simulation program ANSYS is the possibility of solving problems as a whole and the parametrisation of the models. Lateral stiffness of a triple spring is dependent on the end coils mounting position. The results will be further used in simulation of the whole bogie and of its transition in curve using SIMPACK program.

This work was supported by the Cultural and Educational Grant Agency of the Ministry of Education of the Slovak Republic in project No. KEGA 077ŽU4/2017: Modernization of the Vehicles and engines study program. The work was also supported by the project No. APVV-0842-11: Equivalent railway operation load simulator on the roller rig and VEGA No. 1/0558/18: Research of the interaction of a braked railway wheelset and track in simulated operational conditions of a vehicle running in a track on the test stand.

Research-Educational Center of Rail Vehicles (VVCKV)

\section{References}

1. J. Gerlici, T. Lack Applied mechanics and materials. Vol. 486, pp. 396-405 (2014).
2. T. Lack, J. Gerlici, $9^{\text {th }}$ International Conference on Contact Mechanics and Wear of Rail/Wheel System, 87-89 (2012).

3. T. Lack, J. Gerlici, Applied mechanics and materials. 486. 359-370 (2014).

4. T. Lack, J. Gerlici, Applied mechanics and materials. 486. 371-378 (2014).

5. T. Lack, J. Gerlici, Communications - Scientific Letters of the University of Žilina. 7, 38-45 (2005).

6. T. Lack, J. Gerlici, Communications - Scientific Letters of the University of Žilina. 15, 126-132 (2013).

7. J. Gerlici, T. Lack, An international journal on the science and technology of friction, lubrication and wear. 271, Sp. iss., 246-258 (2011).

8. J. Gerlici, T. Lack, Procedia Engineering. . 2, 1, 2249-2257 (2010).

9. J. Gerlici, T. Lack, Applied mechanics and materials. 486, pp. 379-386 (2014).

10. P. Baran, M. Brezáni, P. Kukuča, P. Št’astniak, Procedia Engineering. 192. 34-39 (2017).

11. V. Hauser, et. al., Procedia Engineering. 192, 289294 (2017).

12. V. Hauser, et. al., Procedia Engineering, 192. 295300 (2017).

13. Simpack 9.9.2 Documentation. 4556p (2016).

14. G. Fedorko, V. Molnár, J. Strohmandl et al. Transport Means 2015 - Proceedings of the International Conference. 466-+ (2015)

15. P. Baran, P. Št’astniak, P. Kukuča, M. Brezáni, MATEC Web of conferences. 157, 02003 (2018). DOI: https://doi.org/10.1051/matecconf/20181570200 